
\title{
Research Suute \\ Determinants of quality of life and life satisfaction of urban residents
}

Hubert Kotarski ( $\sim$ kotarski@ur.edu.pl )

University of Rzeszów

Research article

Keywords: quality of life, city, residents, Rzeszow, welfare, life situation

Posted Date: September 9th, 2020

DOI: https://doi.org/10.21203/rs.3.rs-28466/v2

License: (c) (i) This work is licensed under a Creative Commons Attribution 4.0 International License.

Read Full License 
Hubert Kotarski, Ph.D.

University of Rzeszów, College of Social Sciences, Institute of Sociology

Al. Rejtana 16c, 35-959 Rzeszów, Poland

e-mail; kotarski@ur.edu.pl

\title{
Determinants of quality of life and life satisfaction of urban residents
}

\begin{abstract}
Background: The assessment of quality of life and life satisfaction of Rzeszow residents aged 18-75 using a WHOQOL-BREF questionnaire which consists of 26 questions and analyses 4 basic domains of quality of life: physical, psychological, social relationships, functional environment of the respondent and a global quality of life and self-assessment of one's health.

Methods: The survey was conducted on a representative sample of 618 adult residents of Rzeszow (Poland; population: 195 031). Respondents were randomly selected through systematic random sampling with latent layer division from the population register shared by Rzeszow Municipal Office.

Results: Good scale score reliability for the entire tool was confirmed in the study population: the Cronbach's $\alpha$ compatibility coefficient for sub-tests (four domains) between $0.746-0.848$, and for the entire test -0.921 . The results indicate that gender does not differentiate the quality of life of Rzeszow residents. However, the quality of life is affected by age, education, financial situation, and body mass index.
\end{abstract}

Conclusions: I found that the WHOQOL-BREF questionnaire is an interesting research tool when analysing the quality of life and may be useful in comparative studies of the quality of life of the residents of cities/towns, counties or regions.

Keywords: quality of life, city, residents, Rzeszow, welfare, life situation

\section{Background}

In its ordinary meaning the quality of life is an intuitively understood and comprehensible category. From a scientific point of view, it is a term lacking a universally accepted definition, which creates major methodological problems. It belongs to general, difficult to define terms, similar to other concepts with existential colouring such as: "the meaning of life", "happiness", which have been the subject of philosophical deliberations for millennia [Kałamucka 2017, p. 42]. Not surprisingly then, there is a widespread belief that the quality of life is a multidimensional, emotionally loaded concept and phenomenon, often ideologically instrumental, an evaluative concept that is impossible to determine without ambiguity, entangled in political and cultural contexts [Adamiec, Popiołek 1993]. Scientific interest in the quality of life issues has a relatively short history, dating back to the 60s of the 20th 
century. The emergence of the concept of the quality of life was associated with economic growth in the United States. Prior to this, the quality of life was a rather occasional topic of a public debate, even though the issues associated with it, mainly concerning the search for the determinants of a happy and worthwhile life, has accompanied the man since ancient times. Initially, the research on the quality of life was mainly related to objective indicators of the degree of satisfaction of needs. The last several years show an emerging trend to broaden the perspective in which this issue is dealt with [Mularska-Kucharek 2013, p. 41]. Today, this concept has become a permanent position in terminologies of such sciences as sociology, medicine, economics, psychology and pedagogics. In the 1960s and 1970s two directions evolved for considering issues associated with quality of life. Within the scope of the first, the phrase "quality of life" was used as a value determinant. The rising outcry against the consumer society in the United States brought with it a growing popularity of an alternative lifestyle. Its proponents propagated a new quality of life. They opposed economic development solely geared towards increasing consumption, one which destroys the natural environment and social ties. The second direction for considering the quality of life issue, referred to as the social indicators movement by Otis Duncan, takes root in the field of social research. The quality of life concept which emerged from this field, identified it with indices measuring the material standard of life and/or life satisfaction levels. A vibrant discourse is still underway to this day within that field, concerning indicators measuring quality of life on individual as well as population levels. The gross national income per capita is generally adopted as a quality of life measure, although many authors point out the limitations of such an index. The main criticism concerns the fact that income does not reflect cultural differences. Neither does it reflect the distributive nature of an economy. It does not take into account the fact that when it comes to financial situations, modern societies are internally diverse [Rokicka 2013, p. 159-160].

Representatives of numerous scientific disciplines including pedagogy, psychology, sociology and medicine show an avid interest in the quality of life concept which, on the one hand, ensures it is considered in a multifaceted complementary manner from a multidisciplinary perspective, whilst on the other, it leads to a multiplicity of different understandings of the concept and in turn inconsistencies in its operationalization [Petelewicz, Drabowicz, 2016: 13]. Ewa Rokicka, in her attempt to systematize various quality of life areas of interest, identified five primary trends:

1) a trend focusing on the protection of the natural environment - depicts the consequences of civilizational progress for the natural environment, human health and quality of life, amongst others as a result of air, water and noise pollution, etc.;

2) a trend associated health measures - in medicinal sciences, Health Related Quality of Life (HRQoL), understood as a patient's self-assessment pertaining to the impact of an illness and the administered treatment on their physical, psychological and social functioning, is looked upon as a health measure on par with medical health measures. The HRQoL index shows whether, despite an illness, a patient perceives themselves to function well within the aforementioned scopes, or whether they consider the illness to restrict those functions; 
3) a trend which pertains to urbanisation issues - here, attention is particularly devoted to unfavourable consequences of scientific and technological progress within urban areas, such as: incorrect spatial planning for cities, residential accommodation, excessive vehicular traffic, high density of urban agglomerations;

4) a trend based on social and psychological motives - focuses on the negative consequences of civilizational progress for individuals and the social life; these include: self-alienation, social alienation, estrangement, emptiness and loneliness experienced by people;

5) a trend which focuses on the economic aspect of life - quality understood as the living standard of an individual, local, regional, national or international communities, it may be interchangeably treated as a dependent variable as well as the independent variable, as a factor determining economic development and the results thereof. The level of wealth and poverty and their unequal distribution are significant for the individual's and society's quality of life [Rokicka 2013, p. 161]. It should be pointed out that a two-fold approach to quality of life is evident in all five trends. On the one hand, it may be seen as a value determinant of a comparative nature, and on the other, as descriptive and not determining value. To a certain extent, the quality of life issue itself is a value determinant. Both authors as well as those who assess their own quality of life represent various philosophical notions on life, different ideological orientations, their moral values' hierarchies as well as life experiences which affect psyche are diverse. They judge according to their own criteria, knowledge, standards and comparative points of reference [Rokicka, Petelewicz, 2014: 144].

A review of the literature related to the research on the quality of life reveals many ambiguities, both in the meaning of the concept and in its definitions. Controversies over this issue appear not only in various social sciences, but also concern representatives of the same field of knowledge. This situation is mainly due to researchers focusing on different aspects of the quality of life and the interdisciplinary nature of this concept. Social sciences take a joint position when stating that what counts in determining the scope of the term of the quality of life is the analysis of both objective and subjective determinants [Sompolska-Rzechuła 2013, p. 127]. Confirmation supporting this thesis provides the literature analysis, in which one can find many models used to measure the quality of life referring to objective and subjective determinants. Some of them are based on objective, some on subjective aspects of the quality of life. There are also proposed mixed models which take into account both objective and subjective dimension of the phenomenon [Michalska-Żyła, 2015, p. 149]. An interesting review of the methods of researching the quality of life studies was presented by Heather Dunning [Dunning 2004].

For several years, there can be observed an increasing interest in the quality of life issues. It is visible both in case of social scientists, as well as representatives of medical sciences and health sciences. Since 1972, we have observed a constant and spectacular growth in the number of studies and published scientific works related to the discussed issues. Considering all publications in which the slogan "quality of life" appeared in the title compared to the previous decade, we can notice a gradual increase in the number of publications. A similar dynamic is observable in scientific articles in which the slogan 
"quality of life" has been used as a keyword. In 1981 there was found more than a 328-fold increase in the number of these publications compared to the year 1971. In 1991 an almost four-fold increase compared to the previous period, in 2001 - the next nearly four-fold increase, in 2011 - another more than twofold growth in the number of articles. Analysing the number of publications in which the slogan "quality of life" was used in the articles contents, it was found that in 1981 there was a 57 -fold increase in the number of scientific texts in comparison with 1971. In 1991 there was recorded a fourfold increase in the number of publications in relation to the previous period, in 2001 - a four and a half fold increase, and in 2011 less than a threefold increase in the number of scientific articles [Kukielczak 2012, p. 542543].

The social sciences still have not developed a generally acceptable universal definition of the quality of life. Researchers are rather trying to conceptualize this term, having then a primary focus on the context of its use and the purpose of the research [Trzebiatowski 2011, p. 26]. Finding a compromise for the definition of the quality of life is not easy. Liu pointed out in 1976 that there are so many definitions of the quality of life as there are people [Rokicka 2013, p. 165]. These problems make it difficult to identify a comprehensive definition of the quality of life, which would be fully useful for researchers representing various sciences. One of the most frequently used and widely quoted definition was formulated by the Quality of Life Group, acting in the framework of the World Health Organization (WHOQOL Group). The quality of life is defined as the individual's perception of their position in life in the context of culture and value systems accepted by the society in which they live, and in relation to their life goals, expectations and interests [Pluta 2010, p. 275]. Representatives of various sciences are also largely interested in the issue of different operationalizations of the concept itself. It seems that a compromise solution resulting from the concept's ambiguity is to conduct a comprehensive study of the quality of life in a multi-faceted way. An interesting concept of term systematization is the proposal of Jacek Trzebiatowski, who proposes to divide definitions formed in social sciences into four groups in order to organise them. The first one includes definitions which he called "existential", the other definitions focusing on tasks that can be described as "vital", the third group places the quality of life in the category of needs, whereas the fourth one is made up of the definitions that distinguish objective and subjective stream of the quality of life while taking into account the concept of needs [Trzebiatowski 2011, p. 26].

\section{Methods}

The paper will present the results of the research conducted in 2017 in Rzeszów under the title "Rzeszow Social Diagnosis 2017". The survey was conducted on a representative sample of 618 adult residents of Rzeszow. Respondents were randomly selected from the population register, made available by Rzeszow Municipal Office. In order to provide a representative sample the author applied a systematic randomization with a latent layer division. The sampling frame was organised by gender, residence and age of Rzeszow residents. By this arrangement of sampling it was also possible to choose the appropriate 
sample reserve in case of the core sample persons' refusal to participate in the survey. In the case of such a refusal, a core sample person was replaced by another person of the same sex, living in the same estate and of the same age. Assuming, therefore, that the respondents participating in the study did not differ significantly from respondents who refused to participate in the study, it can be estimated that the error from the sample does not exceed $3.5 \%$ at a confidence level of $95 \%$, and the results obtained with such accuracy could be generalized on the population.

The growing importance of research on the quality of life is accompanied by the need for measurement tools. The most practical and reliable method of data collection are standardized questionnaires. Currently, there is a rich source of measuring scales, characterized by high reliability and suitable psychometric properties even in the case of their repeated use during one study [Krzysztoszek, Koligat, Nowakowska 2015, p. 178]. Having regard to the foregoing, a research tool used to assess the quality of life of the adult residents of Rzeszow was WHOQOL questionnaire - WHOQOL-BREF version (World Health Organization Quality of Life BREF - Assessment Instrument: short version) [The WHOQOL Group 1998]. It is a questionnaire for a psychometric assessment of the quality of life. It analyses in a five-point scale an emotional state and physical condition of the respondent [Kłak, Mińko, Siwczyńska 2012, p. 635]. WHOQOL tools are available in two different versions: WHOQOL 100 and WHOQOL-BREF. The authors of Polish version are Laura Wołowicka and Krystyna Jaracz. WHOQOL 100 contains 100 questions, it analyses 8 domains of life, 24 categories, global quality of life, selfassessment of one's health. WHOQOL Bref contains 26 questions, it analyses 4 basic domains of life. 24 categories and a global quality of life and self-assessment of one's health.[Wołowicka, Jaracz 2001, p. 196-197]. A detailed description of the variables used to determine the level of quality of life and selfassessment of one's health is as follows:

- Domain 1 - Physical Domain:

- everyday activities,

- dependence on drugs and treatment,

- energy and fatigue,

- mobility,

- pain and discomfort,

- rest and sleep,

- ability to work.

- Domain 2 - Psychological Domain:

- appearance,

- negative feelings,

- positive feelings,

- self-esteem,

- spirituality, religion, personal faith, 
- thinking, learning, memory, concentration.

- Domain 3 - Domain of Social Relations:

- personal relationships,

- social support, .

- sexual activity

- Domain 4 - Functional Environment:

- financial resources,

- freedom, physical and mental security

- health and health care (availability and quality),

- home environment,

- opportunities to acquire new information and skills,

- and recreation and leisure opportunities,

- physical environment (pollution, noise, traffic, climate),

- transportation.

The WHOQOL-BREF questionnaire is useful in epidemiological studies and clinical trialswhere quality of life is of interest [The WHOQOL Group 1998]. In addition, the WHOQOL-BREF questionnaire was translated and tested for use in Poland according to the WHO's international guidelines [Jaracz, Kalfoss, Górna, Baczyk 2006]. Moreover, WHOQOL-BREF also includes two items analysed separately - individual overall assessment of the quality of life and individual overall assessment of the respondent's health. The scale of assessment of particular domains has a positive direction - the higher the scale, the better the quality of life. The domains scores are determined by calculating the arithmetic average of the items included in individual domains. The applied WHOQOLBREF tool has the Cronbach's $\alpha$ compatibility coefficient for sub-tests (four domains) between 0.7460.848 , and for the entire test -0.921 .

\section{Results}

The study included 618 residents of Rzeszow aged 18 - 75 years. The average age of respondents was 43.2 years, the median 41 years and the dominant 38 years. The surveyed population was dominated by women, who accounted for $53.2 \%$ of the respondents, the percentage of men was $46.8 \%$. Respondents differed in terms of the level of education. The largest category were people with higher (47.0\%) and average (38.8\%) education. Respondents with vocational education represented $12.1 \%$ and primary and lower education had $2.1 \%$ of them.

Table 1 shows the results of WHOQOL-BREF test in individual domains in the entire studied population of Rzeszow residents.

Table 1. The quality of life of residents in individual domains of WHOQOL-BREF tests

\begin{tabular}{|c|c|c|c|c|}
\hline Domain & Minimum & Maximum & Mean & $\begin{array}{c}\text { Standard } \\
\text { deviation }\end{array}$ \\
\hline
\end{tabular}




\begin{tabular}{|c|c|c|c|c|}
\hline Overall quality of life, WHO1 & 1 & 5 & 3.90 & 0.71 \\
\hline $\begin{array}{c}\text { Self-assessment of the respondent's health, } \\
\text { WHO2 }\end{array}$ & 1 & 5 & 3.84 & 0.86 \\
\hline Physical Domain, DOM1 & 6.29 & 20.00 & 15.93 & 2.62 \\
\hline Psychological Domain, DOM2 & 9.33 & 20.00 & 16.05 & 2.34 \\
\hline Social Relations, DOM3 & 8.00 & 20.00 & 15.94 & 2.60 \\
\hline Functional Environment, DOM4 & 7.00 & 20.00 & 14.74 & 2.16 \\
\hline
\end{tabular}

Source: own research.

Overall quality of life measured on a five-point scale (1-5 scale) for the variable "individual overall assessment of the quality of life" (WHO1) was high. The variable average was $M=3.90 ; S D=0.71$. For almost every sixth respondent residing in Rzeszow the overall assessment of the quality of life was very good $(17 \%)$, more than half considered that the assessment is good $(52.7 \%)$. The quality of life was rated as poor or very poor by less than three percent of the respondents $(0.5 \%$ - very bad, $2.1 \%$ - bad). Every fifth respondent could not state clearly whether it is good or bad, by answering "neither good nor bad" $(21.1 \%)$. Slightly lower values were reported for the variable "self-assessment of one's health" (WHO2). The average was $M=3.84 ; S D=0.86$. Every fifth respondent was very satisfied (20.1\%), while more than half were satisfied with their health (52.7\%). Less than eight percent of Rzeszow residents were dissatisfied $(6.6 \%)$ or very dissatisfied $(1.2 \%)$ when assessing their health condition. Every fifth respondent was ambivalent in their health assessment, stating that they are "neither satisfied nor dissatisfied" (19.4\%).

The use of sociodemographic variables in the analysis of variables constituting dimensions of the quality of life: WHO1, WHO2, DOM1, DOM2, DOM3, DOM4 showed that the variable of gender does not differentiate in a statistically significant way the overall assessment of the quality of life, health condition or the quality of life in the four highlighted domains. The factor which significantly differentiated the assessments was the age of the respondents. A negative Spearman's rank correlation coefficient indicates that the assessment of the overall quality of life, health condition and the quality of life in its four domains worsens with age. The older the respondent, the worse is the assessment. This correlation is most strongly evident in the physical domain of the quality of life and in self-assessment of one's health. Age is the factor the least differentiating the assessment in the psychological domain of the quality of life and in social relationships of the surveyed.

Table 2. Results of WHOQOL-BREF tests in individual domains and the respondents' age

\begin{tabular}{|c|c|c|}
\hline Domain & Test Value & Statistical Significance \\
\hline Overall quality of life, WHO1 & $-0.196^{*}$ & 0.001 \\
\hline Self-assessment of the respondent's health, WHO2 & $-0.281^{*}$ & 0.001 \\
\hline Physical Domain, DOM1 & $-0.320^{*}$ & 0.001 \\
\hline Psychological Domain, DOM2 & $-0.123^{*}$ & 0.001 \\
\hline Social Relations, DOM3 & $-0.181^{*}$ & 0.001 \\
\hline Functional Environment, DOM4 & $-0.146^{*}$ & \\
\hline
\end{tabular}

* Evaluation using Spearman's rank correlation coefficient.

Source: own research. 
Analysis of individual variables that make up the psychological domain of DOM 2 indicated that the age has the greatest negative impact on the number of happy moments in the respondents' lives (rho = $0.146 ; p<0.001$ ) and the level of self-satisfaction (rho $=-0.128 ; p<0.001$ ). In the field of social relations DOM3 the age was in correlation with two variables forming this domain - the level of respondents' satisfaction with their intimate lives $(r h o=-0.230 ; p<0.001)$ and the level of satisfaction with the support they get from their friends ( $r h o=-0.146 ; p<0.001)$.

Similarly, the respondents' education proved to be the factor that determines the assessment of particular domains of the quality of life of Rzeszow residents. Positive values of the Spearman's rank correlation coefficient indicate that a higher score in the parameters that make up an individual assessment of different domains of the quality of life is associated with a higher level of education. Better educated people give a better assessment of individual quality of life domains than people with lower levels of education. Most evident correlation between the level of education and individual assessment of the quality of life can be seen in the case of physical domain (DOM1) and the domain of social relations (DOM3). In these two cases the coefficient is the highest. It can be therefore arguably claimed that an investment in education translates into a higher quality of life. This dependency may be associated with mental type of work dominant among people with higher level of education, a better financial situation or greater awareness of the need for prevention and care of their health.

Table 3. Results of WHOQOL-BREF tests in individual domains and the respondents' education

\begin{tabular}{|c|c|c|}
\hline Domain & Test Value & Statistical Significance \\
\hline Overall quality of life, WHO1 & $0.207^{*}$ & 0.001 \\
\hline Self-assessment of the respondent's health, WHO2 & $0.262^{*}$ & 0.001 \\
\hline Physical Domain, DOM1 & $0.304^{*}$ & 0.001 \\
\hline Psychological Domain, DOM2 & $0.240^{*}$ & 0.001 \\
\hline Social Relations, DOM3 & $0.300 *$ & 0.001 \\
\hline Functional Environment, DOM4 & $0.254^{*}$ & \\
\hline
\end{tabular}

* Assessment with the use of Spearman's rank correlation coefficient.

Source: own research.

The factor that was used to analyse particular domains of the quality of life was also financial situation of the respondents. It was determined by using questions with five-grade scale: 1) We live very poorly, we do not have enough even for our basic needs; 2) We live modestly, we need to live economically every day; 3) We live an average life, we have enough money for everyday needs, but we need to save for major purchases; 4) We live well enough without many special savings; 5) We live very well compared to others, we can afford the luxury. The analyses have shown that there is a statistically significant relationship between the financial situation of the respondents and individual assessment of the quality of life. The correlations were statistically significant for the overall quality of life, health assessment and the four domains of the quality of life (DOM1, DOM2, and DOM3 DOM4).

Table 4. Results of WHOQOL-BREF tests in individual domains and the respondents' financial situation

\begin{tabular}{|c|c|c|}
\hline Domain & Test Value & Statistical Significance \\
\hline
\end{tabular}




\begin{tabular}{|c|l|l|}
\hline Overall quality of life, WHO1 & $0.370 *$ & 0.001 \\
\hline Self-assessment of the respondent's health, WHO2 & $0.327^{*}$ & 0.001 \\
\hline Physical Domain, DOM1 & $0.290^{*}$ & 0.001 \\
\hline Psychological Domain, DOM2 & $0.300 *$ & 0.001 \\
\hline Social Relations, DOM3 & $0.271^{*}$ & 0.001 \\
\hline Functional Environment, DOM4 & $0.386 *$ & 0.01 \\
\hline
\end{tabular}

* Assessment with the use of Spearman's rank correlation coefficient.

Source: own research.

The highest Spearman's rank correlation coefficient was noted for the correlation between the domain of environment (DOM4) and individual overall assessment of the quality of life (WHO1). The DOM4 domain consists of the following specific variables, such as: health and healthcare, opportunities and participation in recreation and leisure or opportunities to acquire new information and skills. The accessibility of these attributes of the quality of life largely depends on the financial possibilities of an individual and therefore a clear correlation between these variables should not be a surprise.

The Rzeszow Social Diagnosis - 2017 edition - also helped identify other factors that may significantly affect the assessment of the quality of life. One such factor was the body mass index or BMI. Body Mass Index). This is a coefficient derived by dividing the person' weight in kilograms by the square of the person's height in metres. For the purposes of analysis, based on the BMI value two groups of respondents were distinguished: 1) individuals with normal body weight - the BMI between 18.50$24.99 \mathrm{~kg} / \mathrm{m}^{2} ; 2$ ) overweight and obese persons - the BMI of more than $24.99 \mathrm{~kg} / \mathrm{m}^{2}$. The analyses used Student's t-test for independent samples. The study involved 250 people with normal body mass and 207 overweight and obese persons. The BMI index significantly differentiated the levels of assessment of the quality of life in three dimensions - in the overall assessment of the quality of life, the assessment of health condition and the physical domain (DOM1). In the first case - the overall assessment of the quality of life, the average level of the variable among the respondents with normal body mass was higher $(\mathrm{M}=3.96, \mathrm{SD}=0.47)$ than in the overweight and obese respondents $(\mathrm{M}=3.81 ; \mathrm{SD}=0.47)$. Analysis of the results showed that the difference is statistically significant $t(455.0)=2.206 ; p<0.028$. $\eta^{2}=0.011$. The eta squared effect size is average but we can say that Rzeszow residents whose weight is within the range for correct values assess their individual overall quality of life better than those with excess weight and obesity. The second important variable is individual assessment of health condition. The average level of the variable in the respondents with normal body mass was higher $(\mathrm{M}=3.94, \mathrm{SD}=$ $0.89)$ than in subjects with excess weight and obesity $(\mathrm{M}=3.74, \mathrm{SD}=0.84)$. Analysis of the results showed that the difference is statistically significant $\mathrm{t}(453.0)=2.358 ; \mathrm{p}<0.019 ; \eta^{2}=0.012$. Just as in the previously analysed variable the eta squared effect size is average, but in this case as well, it can be stated that Rzeszow residents with normal body mass assess their overall health condition better than those with excess weight and obesity. This result should not be surprising. The third variable that significantly differentiated the assessment of the quality of life was the physical domain (DOM1). As with the overall assessment of the quality of life and the assessment of health condition, this variable is 
also better assessed by respondents of normal body mass $(\mathrm{M}=16.17, \mathrm{SD}=2.65)$ than those who are overweight and obese $(\mathrm{M}=15.51 ; \mathrm{SD}=2.62)$. Analysis of the results showed that the difference is statistically significant $\mathrm{t}(453.0)=2.660 ; \mathrm{p}<0.008 . \eta^{2}=0.015$. The eta squared effect size is large and it can be stated that the respondents with normal body mass consider their quality of life, perceived through the prism of physical ability to function, better than those with excess weight and obesity.

\section{Discussion}

As mentioned in the introduction, the quality of life is a multidimensional concept and phenomenon, difficult to operationalize and measure. The respective domains of the quality of life are characterized by variables describing various aspects. If these variables are directly observable, they become measures of a given quality aspect. The quality of life having a complex nature and at the same time being difficult for direct observation, these variables are not frequently directly observable and hence are called latent variables [Panek 2016, p. 35]. The use of a standardized tool such as a WHOQOL-BREF questionnaire to study the quality of life is a reasonable solution. It is a simple and reliable method for assessing the quality of life.

For the analysis of factors differentiating the assessment of the quality of life the author used sociodemographic variables like gender, age and education as well as social factor variables - the financial situation and body mass index (BMI). The results indicate that gender does not differentiate the quality of life of Rzeszow residents. The quality of life is affected by age, education, financial situation, and body mass index. The quality of life deteriorates with age, which is undoubtedly affected by a natural decrease in the possibilities of active functioning, related to physical limitations of an ageing body. The optimistic conclusion of the analysis is that despite the fact that age is a determinant of deterioration of the quality of life, it is the least significant factor that negatively affects the psychological domain and environmental issues of an individual.

The conclusion that can be drawn from the research is that the quality of life of the Rzeszow residents may depend on the level of education. Their well-being is better assessed by persons with the highest level of education. One can therefore venture to say that investment in education translates into a higher quality of life. This dependency may be associated with mental type of work dominant among people with higher level of education, a better financial situation or greater awareness of the need for prevention and care of their health.

The study also confirmed a popular opinion that social being determines consciousness. The financial situation of the respondents significantly correlated with the assessment of the quality of life. This correlation was the strongest in the case of functional environment of the respondents (DOM4). This domain includes such specific variables as health condition and healthcare, opportunities and participation in recreation and leisure or opportunities to acquire new information and skills. The accessibility of these attributes of the quality of life largely depends on the financial possibilities of an individual and therefore a clear correlation between these variables should not be a surprise. 


\title{
Conclusion
}

The study also made it possible to formulate interesting conclusions related to the physical attributes of respondents carrying, however, consequences of a social nature. Excess weight and obesity are becoming an increasingly common problem of a growing number of inhabitants of Poland and other European countries and North America. The weight surplus and obesity are accompanied by a sharp increase in the incidence of diseases resulting from the excess body fat. People with this type of problems are more prone to cancer, hypertension, heart disease, diabetes or arthrosis and joint diseases. Overweight and obese people found their health condition and quality of life significantly worse in all four analysed domains than people with normal body weight. This fact should certainly call for the emergence of health prevention programs at the local level.

The studies have shown that the WHOQOL-BREF questionnaire is an interesting research tool when analysing the quality of life and may be useful in comparative studies of the quality of life of the residents of cities/towns, counties or regions.

\author{
Abbreviations \\ BMI: Body Mass Index; HRQoL: Health Related Quality of Life; WHOQOL-Bref: World Health \\ Organization Quality Of Life, Short Form; WHO: World Health Organization
}

\section{Declarations}

\section{Ethics approval and consent to participate}

The research project was accepted by the Bioethics Committee of the University of Rzeszow (Resolution No. 17/6/2017). In accordance with Declaration of Helsinki, the participants were provided with information about the aim and the course of the study, and expressed their written and informed consent to participate. The persons were informed about the possibility of withdrawing from the study at any stage of the interview.

\section{Consent for publication}

Not applicable.

\section{Availability of data and material}

The datasets used and analysed during the current study aren't available.

\section{Competing interests}

The author have no conflicts of interest to declare.

\section{Funding}

None. 


\section{Acknowledgements}

None.

\section{Open Access}

This article is distributed under the terms of the Creative Commons Attribution 4.0 International License (http://creativecommons.org/licenses/by/4.0/), which permits unrestricted use, distribution, and reproduction in any medium, provided you give appropriate credit to the original author(s) and the source, provide a link to the Creative Commons license, and indicate if changes were made. The Creative Commons Public Domain Dedication waiver (http://creativecommons.org/publicdomain/zero/1.0/) applies to the data made available in this article, unless otherwise stated.

\section{References}

Adamiec M., Popiołek K., 1993, Quality of life - between freedom and hoax, in Ruch Prawniczy, Ekonomiczny i Socjologiczny, no. 2, p. 93-102.

Dunning H., 2004, A Mixed Method Approach to Quality of Life in Saskatoon, Community-University Institute for Social Research, www.usask.ca/cuisr.

Jaracz K, Kalfoss M, Górna K, Baczyk G. Quality of life in polish respondents: psychometric properties of the polish WHOQOL-Bref. Scand J Caring Sci. 2006;20(3):251-60.

Kałamucka W., 2017, Quality of Life and Social Security from a geographical perspective, published by Wydawnictwo Uniwersytetu Marii Curie-Skłodowskiej, Lublin.

Kłak A., Mińko M., Siwczyńska D., 2012, Questionnaire methods for studying the quality of life , in Probl Hig Epidemiol, no. 93(4), p. 632-638.

Kukielczak A., 2012, Growing interest of medical sciences in the research on the quality of life, in Przegląd Epidemiologiczny, no. 66, p. 539-545.

Krzysztoszek J., Koligat D., Nowakowska E., 2015, Systematic review of generic questionnaires commonly used in studies on the quality of life in Poland, in Polski Przegląd Nauk o Zdrowiu, no. 3 (44), p. 177-182.

Michalska-Żyła A., 2015, Life satisfaction and public confidence in residents of post-industrial cities and towns, in Acta Universitatis Lodziensis, Folia Sociologica no 52, p. 147-168.

Mularska-Kucharek M., 2013, Social capital and the quality of life. On the example of urban communities, published by: Wydawnictwo Uniwersytetu Łódzkiego, Łódź.

Panek T., 2016, Quality of life from conception to measurement, published by: Oficyna Wydawnicza Szkoła Główna Handlowa w Warszawie, Warszawa.

Petelewicz M., Drabowicz T., 2016, Jakość życia - globalnie i lokalnie: Pomiar i wizualizacja, published by: General Sociology Department. Faculty of Economics and Sociology University of Lodz, Łódź.

Pluta J., 2010, Quality of life and lifestyle against the system of collective consumption in Wroclaw, in: Błaszczyk M., Kłopot S.W., Pluta J., (ed.), Social problems in the area of Wroclaw Published by: Wydawnictwo Naukowe Scholar, Warszawa. 
Quality of Life Group, 1998, Development of the World Health Organization WHOQOL-BREF quality of life assessment. The WHOQOL group. Psychol Med. 1998;28(3):551-8.

Rokicka E., 2013, Quality of life - contexts, concepts, interpretations, in: Grotowska-Leder J., Rokicka E., (ed.), New Order? The dynamics of social structures in modern societies. Commemorative book dedicated to Professor Wielisława Warzywoda-Kruszyńska on the occasion of the 45th anniversary of her scientific work and teaching., published by: Wydawnictwo Uniwersytetu Łódzkiego, Łódź.

Rokicka E., Petelewicz M., 2014, Subiektywna jakość życia a status społeczno-ekonomiczny. Na przykładzie mieszkańców Łodzi, in Przegląd Socjologiczny, No. 63/2014(2).

Sompolska-Rzechuła A., 2013, Quality of life as an economic category, Folia Pomer. published by: Univ. Technol. Stetin. 2013, Oeconomica 301 (71), p. 127-140.

The WHOQOL Group, 1998, Development of the World Health Organization WHOQOL-BREF Quality of Life Assessment, Psychological Medicine, Volume 28, Issue 3, p. 551-558.

Trzebiatowski J., 2011, Quality of life in the perspective of medical and social sciences - systematization of definitions, in Hygeia Public Health, no. 46(1), p. 25-31.

Wołowicka, Jaracz K., 2001, WHOQOL-BREF, in: Wołowicka L. (ed.), Quality of life in medical sciences. published by: Wydawnictwo Akademii Medycznej, Poznań. 